This is an Accepted Manuscript of an article published by Taylor \& Francis Group in Cultural Trends on 30/07/2019, available online https://doi.org/10.1080/09548963.2019.1644791

\title{
Crafting the local: the lived experience of craft production in the
}

\section{Northern Isles of Scotland}

\author{
Dr Lynn-Sayers McHattie*, Dr Katherine Champion and Dr Michael \\ Johnson
}

*The Innovation School, The Glasgow School of Art, Glasgow, UK

1.mchattie@gsa.ac.uk

Dr Lynn-Sayers McHattie is Programme Director for research in the Innovation School, The Glasgow School of Art. She is Principal Investigator for Design Innovation for New Growth, AHRC follow-on-funding from Design in Action, an AHRC funded Knowledge Exchange Hub, where she acted as Co-Investigator. Her research interests include craft in the creative and cultural economy that connect to the indigenous landscape and culture of islands.

Dr Katherine Champion is a Lecturer in Media and Communications at the University of Stirling. Her research interests include the spatial organisation of the creative economy, creative labour and cultural and creative industries policy.

Dr Michael Pierre Johnson gained his PhD through Design in Action in 2016, and has since been working in multiple projects of collaborative creative engagement at The Glasgow School of Art. He was recently awarded an AHRC funded Innovation Leadership Fellowship in the Creative Economy. His research interests are on making the effects and viability of Design Innovation approaches more explicit within complex collaborative contexts. 


\section{Crafting the local: the lived experience of craft production in the}

\section{Northern Isles of Scotland}

\section{Abstract}

National creative and cultural industries policy agendas tend to focus on the economic impact of the sector often favouring scalable digital activities based in global clusters, which underpin notions of growth. There has, however, been a re-emergence of craft, which may not be scalable in the same way, into public debate, but which is increasingly recognised as part of a growing industrial sector, with benefits linked to educational, cultural and economic policy agendas. Accordingly, policymakers have begun to view craft as a stimulus to develop local and regional economies, skills and materials in relation to wider networks. Within this push towards craft-driven creative place making and economic growth, it has been argued that more sophisticated understandings of the "local" are needed that go beyond those which are inward and parochial. Based on AHRC-funded empirical research undertaken in the Northern Isles of Scotland with craft practitioners, this article attempts to provide evidence of the place-based nature of craft work highlighting both opportunities as well as constraints linked to contexts that are often referred to as remote and peripheral when contrasted with urban locations. This article argues that there is a dissonance between high-profile creative-economy policies and the political economy of the "lived experience" of craft work in non-metropolitan settings. We argue for future investigation into, what we term, fractal growth - growth and development that considers multiple dimensions - as being a valid and valuable outcome of creative practice, which cannot be easily scaled.

Keywords: craft; local; lived experience; cultural assets; innovation; fractal growth 


\section{Introduction}

Efforts to demonstrate the economic value of the creative industries have been engaged in with "breathless optimism" and have arguably squeezed out any values that fall outside of those related to "growth, innovation and economic metrics" (O'Connor, 2016: 4). National creative and cultural industries policy agendas (Industrial Strategy, Creative Industries: Sector Deal) tend to focus on the economic impact of the creative and cultural industries frequently highlighting the net contribution of the sector to the GDP of the British economy. The recasting of cultural to creative (Garnham, 2005) has not been limited to policymakers, with practitioners and advocates for such activities also embracing the language of growth. As noted within the AHRC's work on cultural value (Crossick \& Kaszynska, 2016), studies of economic impact, often simplistic and limited in use, have become the principal way for a sector to argue its importance. This, asserts O’Connor (2016: 7), in line with other critics and commentators (for example, Bakhshi and Cunningham, 2016; Garnham, 2005; Oakley and O'Connor, 2015), sets a trap resulting in there being "no longer any space to talk about the other values of culture - or at least only as optional add-ons".

Symptomatic of the repositioning from cultural to creative within arts and cultural policy discourses from the late 1990s onwards was the incorporation of the digital content creation industries that are more easily scalable (DCMS, 1998). As a corollary the emphasis within creative industries policy has been the support of growth and scalability - bigger as better - through creative content that is facilitated by technology and/or digitally produced. There is also a preoccupation with businesses, services and products that are transferrable to international markets, with the UK government's Business Secretary Greg Clark noting in his foreword to the Sector Deal that the creative industries have "a critical role to play as the UK exits the European 
Union and we build a Global Britain" (BEIS, 2018: 2). A charge of policy universalism (Pratt, 2009) has been posited, with the tendency to support only those businesses or individuals that fit this mold of entrepreneurial and high-growth-orientated models associated with technology and digital content-creating industries. This has further translated into the funding of academic research in the field with the AHRC-funded Creative Industries Clusters specifically tasked with carrying out R\&D activity that will "lead to growth within the creative industries" (AHRC, 2017: 2) foregrounding questions around the appropriateness and desirability of this "growth hungry agenda" (Banks, 2018). The contention being that the emphasis has been the support of economic growth and scalability as a defining construct in cultural and creative policy.

\section{Crafting the Local}

Recently, there has been a re-emergence of craft into public debate, which despite being less scalable, sees such activities increasingly recognised as part of this growing industrial sector with benefits linked to educational, cultural and economic policy agendas (Jakob \& Thomas, 2015). There is increasing interest from policymakers who view craft as a stimulus to develop local and regional economies, skills and materials in relation to wider networks (Luckman, 2013, 2015; Marksuen, 2007; Nesta, 2007; Yair, 2011).

Based on AHRC-funded empirical research undertaken with craft and creative practitioners in the Highlands and Islands of Scotland and specifically focusing on the accounts of craft practitioners based in the Northern Isles, this paper attempts to examine the practices of cultural and creative production in contexts that are often referred to as remote and peripheral when contrasted with urban locations, and the policy dissonance in this context. 
Whilst this characterisation of remoteness can be critiqued in line with the work of Gibson (2012) and others (including Bell and Jayne, 2010; Luckman, 2012) who present evidence for creativity beyond the city, the archipelagos do face challenges that can be associated with their island status. Small islands commonly have narrow economic bases, sensitive coastlines, transport issues, a higher cost per capita of providing basic services and demographic volatility (Jackson, 2006: 201). Through presenting the experiences of those engaged in craft practice in distributed contexts across the Northern Isles, this article argues that there is a dissonance between national and international creative and cultural industries policies and the political economy of the lived experience of craft work in non-urban settings, which results in a lack of support for small and micro creative practitioners whose work is not easily scalable. At worst this dissonance can result in a formulaic, "standard "creative script"” (Bell and Jayne, 2010: 210) with approaches being imposed on places and "running roughshod over local needs, aspirations and already existing or vernacular creative expressions" (Luckman et al, 2009: 72).

\section{Craft and the Creative Economy}

According to the DCMS (2018), the creative industries continue to be one of the strongest performing parts of the economy contributing $£ 101.5 \mathrm{bn}$ to the UK economy in 2017 and accounting for 5.5\% of UK GVA. Between 2010 and 2017 their GVA increased by $53.1 \%$ nearly twice as fast as the UK's $28.7 \%$ increase. Despite the inclusion of crafts in the creative industries definition since the birth of the term in 1998, advocacy around the creative and cultural industries sector often emphasises digital media activities to the exclusion of the material practices of the craft sector. In some ways this is linked to the real challenge of measuring the size and value of the sector. Research commissioned by the Crafts Council (TBR, 2014) has sought to more 
fully account for the economic contribution of crafts, expanding the estimates to a wider definition that includes micro-businesses and the contribution of craft workers who work outside the creative industries as "embedded" workers. Difficulties in measuring the scale of the sector are linked to the nature of the work, with more than three-quarters of craft workers undertaking portfolio careers and with high proportions of selfemployment (BOP, 2012; TBR, 2014). Indeed, the DCMS (2016) have acknowledged that their estimates are likely to significantly underestimate the scale of the craft industry, which was reported to constitute just $0.3 \%$ (around $£ 288$ million) of the total Creative Industries GVA in 2014 (2016: 11).

Although craft is mentioned within the recent Industrial Strategy Creative Industries Sector Deal (BEIS and DCMS, 2018: 2), many of the propositions that follow seem at odds with what we know about the characteristics and priorities of the sector such as funding for cutting edge immersive technology or R\&D partnerships (BEIS, 2018). While the strategy is based around rebalancing the UK creative and cultural industries sector to include areas beyond London and the South East, this does not go much beyond large metropolitan centers with much of the discourses, being largely devoted to the language of clusters, world class talent pools and pipelines of investable businesses (BEIS, 2018).

There has also been a longstanding obscuring of the role that craft plays in contributing to cultural identity and economic production linked to the levels of informal labour and the highly gendered undertaking of such work. The sector is heavily female (BOP, 2012) and, as Abrams argues, "the vicissitudes of the census data recording women's work are well known to historians; suffice to say here that work conducted at home or regarded as assisting in the family enterprise was seriously underrecorded" (2006: 154). Despite the presentation of hand-knitting as a domestic 
handicraft, for example, in Shetland during the nineteenth and much of the twentieth century it integrated women into the market and enabled them to construct an identity for themselves based on their relationship with production and the wider economy (Abrams, 2006). Further to this although home-based work offered possible integration into the market, "piecework" has been marked by structural inequalities and exploitation and it has been argued that the often domestic location associated with many craft practices have impacted on the status of craft (Luckman, 2015: 89). This historical denigration of craft work with high proportions of women homeworking as informal labour can be associated with a tendency to view the sector as hobbyist, with activities undertaken for leisure in order to generate "pin money" (Luckman, 2015).

The recent revitalisation and re-imaging of craft (Jakob \& Thomas, 2015; Luckman, 2015; Luckman and Thomas, 2018) has nonetheless brought the sector greater visibility, in part linked to its progressive associations. Contemporary practices of craft are increasingly linked with agendas of emancipation, individualisation, environmental sustainability and locally-rooted ethical production and consumption (Jakob \& Thomas, 2015). These positive associations are directly rooted in images of the sector as small-scale and micro, artisanal, handmade and local or place-based, all characterisations that would appear at odds with the aforementioned over-arching narratives of the creative economy.

\section{Craft in the Northern Isles}

The Highlands and Islands (H\&I) of Scotland, and specifically the Northern Isles of Orkney and Shetland, which constitute the focus of this article, have a rich history of craft work (for example, Abrams 2006; Bunn 2015; McHattie, Champion \& Broadley 2018; and Turney 2009). Highlands and Islands Enterprise (HIE), the economic and community development agency for the region, have 
publicly expressed a demand for supporting "emerging and established creative entrepreneurs with the aptitude, flexibility and tenacity to build dynamic, innovative, sustainable and competitive creative businesses within the H\&I region" (2013: 4).

The empirical data informing this paper is drawn from a two-year follow-on project Design Innovation for New Growth (DING) funded by the Arts and Humanities Research Council (AHRC), which ran from January 2017 - January 2019, and aimed to deliver Design Innovation as a strategy for supporting practitioners in the creative economy of the H\&I region. DING built on the approaches, activities and knowledge generated from the AHRC-funded Knowledge Exchange (KE) Hub Design in Action (DiA) and applied them within a new geographical context, the H\&I region.

The DING research team comprised of the three authors of this article, and included stakeholders and participants from the Northern Isles who were actively engaged in craft work. During early 2017 a scoping phase with stakeholders in craft, creative practice and cultural policy was undertaken in both Shetland and Orkney. During the research period 2017 - 19 DING delivered six DING studios - design-led knowledge exchange workshops - to a cohort of over 40 creative practitioners, four of the DING Studios were held in the Northern Isles, two in Lerwick, Shetland; and two in Kirkwall, Orkney. The scoping phase identified innovation challenges that craft and creative practitioners faced, which the DING studio workshops responded to through bringing together existing creative businesses, practitioners and experts to learn new design innovation approaches and develop collaborative creative projects. A key insight from the workshop series revealed that creative practitioners in the region faced challenges in finding time and resource to innovate their practice. Therefore, in January 2018, we worked together with stakeholders to develop a DING Innovation Collective 
offering support for innovative projects that advanced the development of creative practice.

In the latter part of the project interviews were carried out with practitioners that had taken part in the project - as a workshop participant or as part of the Innovation Collective. In total nineteen interviews were carried out with craft practitioners in the Northern Isles, eleven in Orkney and eight in Shetland during June - July 2018. The craft practices of the sample varied but included printmaking, textiles, weaving, jewellery, furniture, wood turning, sculpting, metal work, glass making, basket weaving and knitting. Semi-structured interviews offered a useful mechanism for capturing the reflections of craft workers on the lived experiences of their practice in non-urban locations in their own expression and dialect. We thematically analysed the transcripts and selected quotes that resonated with the key themes of culturally located place-based perspectives; temporal and spatial perspectives; and collaborative and collective perspectives, which we discuss in the next section. In order to be concise, we have limited the scope of this article by reflecting only on the empirical work relating to the Northern Isles of Orkney and Shetland.

\section{The Lived Experience of Craft}

The interviews with craft practitioners based in the Northern Isles carried out during the delivery of DING allowed us to garner insights into the experiences of practitioners in the region uniquely related to the local lived experience of craft work and the attendant complex social relations.

Existing research accounts have identified the complex interplay between material practices and the socio-economic and cultural histories of remote or islandbased communities (for example, Abrams, 2006; Luckman, 2012). This relates to the policy dissonance discourses mentioned earlier with issues around a lack of visibility 
and attribution of value to craft work due to its highly gendered associations. This was highlighted by a knitting practitioner in Shetland:

When I started knitting to sell, folk locally didna rate knitting at all, they were very dismissive of knitting. Partly a sort of male/female thing too, it was something that women did so it didna coont for anything and everybody could do it so they didn't see its value (Shetland, Craft Practitioner 5).

\section{Place-based Perspectives}

We now go on to trace the key themes of culturally located place-based perspectives; temporal and spatial perspectives; and collaborative and collective perspectives as evidenced by the participant narratives.

The interviewees regarded their creative practice and the craft work they produced as highly contextually situated and deeply rooted in culturally located place-based perspectives - from the landscape and weather to the cultural heritage - that inspired them.

\footnotetext{
It's somewhere that inspires me landscape-wise and weather-wise [...] I'm part of the landscape and so much part of the weather and everything that goes on, and I love that, that to me is so important (Orkney, Craft Practitioner 9).
}

Participants also reflected on the significant role place and particularly the locale played in constructing their individual and cultural identity and the economic production of craft.

I'm not doing it to be commercial it's been absorbed into me practice [...] Shetland was what I know and it's places I've been so I think fae that point of view, I can see how a sense of place pervades my work and it seems - it seems pointless noo fighting against it. If you get what I mean? I think I just have to accept that I do 
come fae here and it does influence what I do and I've accepted that (Shetland, Craft Practitioner 5).

Participants mentioned the importance of the natural assets and resources of the islands and island life invoking ideas around limitations inspiring creativity and innovation.

I'm not working with York stone and all the lovely beautiful stones that they have sooth. It's quite limited but I quite like that limitation; to only use what I can get locally (Orkney, Craft Practitioner 9).

The islands were viewed as a locus of skills and activities connected to cultural heritage, and the high quality of the work crafted locally. There was a strong sense of place and this was linked to the reputation of craft located there.

Part of my logo is 'handmade in Orkney', I think people that visit Orkney, they sort of fall in love with it. Orkney people are very proud of things that are made in Orkney so that's good but also outwith Orkney, they hear about Orkney and it's got a good reputation for crafts so it's a mark of quality (Orkney, Craft Practitioner 5).

Place identity was seen as something to be capitalised on, although tensions arose from the often negative urban views of rural and remote regions and, in particular, of their social and cultural standing. This chimes with the work of Gibson (2012) and his reflections on the image problems of creative activities found in rural Australia consigned on occasion to "perennial peripherality" (2012: 4).

I think a lot of the time growing up here, you could sort of maybe feel you were being looked down on by a lot of people. And then I went to university and if you said you come from Shetland, you are a yokel or something. Not that many people 
would go 'wow', it was mostly, 'do you have any electricity up there, do you drive cars?' It was always quite negative. So I think I'd grown up with that (Shetland, Craft Practitioner 6).

When I started making I didna want Made in Shetland written on any of my packaging, I didn't want to be known as a Shetland designer. At that time Shetland was kind of un-cool and I also didna want to be riding on the back $o^{\prime}$ it, kind of thing. I didn't want to be limited by my place [...] Because there's a whole rural/urban thing and generally, if you are fae a rural area, folk from urban areas think that you are backward in your social knowledge (Shetland, Craft Practitioner $5)$.

Culturally located place-based perspectives connect to intangible and tangible cultural assets, which are inextricable from a particular locale, for example, vernacular materials, history, skills, indigenous traditions and physical attributes. The richness of the place-based narratives and the tensions articulated by the craft practitioners accounts have evolved through being part of the DING Innovation Collective with their work being supported by Visual Arts and Makers Awards (VACMA) and commissioned for exhibitions in Glasgow and "Shetland Made" in the Bonhoga Gallery, Shetland. Through supporting craft practitioners work their place-based identity narratives have broken beyond the ties of traditional urban/rural stereotyping and contributed to the practitioners' personal identity scripts and self-esteem. That being said the deeply located and lived experience of place-based perspectives require also to be attendant to the Northern Isles zeitgeist and the paradox inherent in the increase in cultural tourism $(\mathrm{McHattie}$, Champion \& Broadley, 2018) and the pressures on island identity and infrastructure. 


\section{Temporal and Spatial Perspectives}

Participants reported particular issues around the limitations of their workspace - space and time - especially those who work from home or near home, often for child care reasons. The limitations of space and time are distinct issues, albeit interwoven, that were referred to in participants accounts where time spent in their studio or workspace was dedicated to making work to order rather than having time to create new developments and collaborations. Echoing the findings of Luckman, Andrew and Crisp (2018) around the complexities of maintaining work boundaries and discipline when working from home as well as compromises and trade-offs over time.

Although it's great because I can work around the family, it's very difficult working at home, working fae home, I do find that quite hard (Shetland Craft Practitioner $5)$.

I'm actually in the process of trying to get funding, working through an application to build a slightly more purpose-built workshop - come visitor centre next to my house [...] But since 2012 I've been working out of a portacabin which serves a purpose but it's too small (Shetland, Craft Practitioner 6).

Creative practitioners are invested in their island communities and their rurality on a number of levels, contributing to community resilience through building cultural capital in diverse ways (Roberts \& Townsend, 2015). Understanding the complexity of undertaking multiple working roles in rural communities, we posit is a first step in understanding how the time-poor nature of portfolio workers could be addressed to open up time and space for innovation.

They've got two or three jobs to try and mak' ends meet because there's no enough work for one job. And I kind of think that affects craft workers; it's very difficult to 
be a full-time craft worker here, I think. Maybe it's just that I find it difficult but I don't know about other folk but quite a lot of the folk are either retired or they are doing it as a hobby or they've got another job and they are doing it as a supplement to their main income (Shetland, Craft Practitioner 5).

The complexity of craft workers undertaking multiple activities has a direct effect on the amount of time practitioners can spend on advancing or innovating their practice or craft work, Sennett (2009) asserts that it takes 10,000 hours of practice to hone craft skills. Temporal and spatial perspectives include balancing multiple roles, including caring, family, distance and workspace limitations are cited as complexities within craft workers lived experiences. These multiple dimensions and the often pejorative language used around "lifestyle choices" levied against women in the main, it can be argued are not through the choice of craft workers, but through the lack of choice to undertake full time craft work.

\section{Collaborative and Collective Perspectives}

Collaborative and collective perspectives are predicated on "collective wisdom" - a shared stock of assets as a form of collective cultural capital - enmeshed within the complex social relationships evident in island communities. This nexus of social interactions is complex, often including invisible and intangible social contracts and cultures of reciprocity; these were cited as extremely important within the accounts of the participants.

There are a whole lot of community links that are quite invisible. For myself, that enable me to work. I was talking about recycled metals and I met the postie a couple of days ago and he said, 'oh do you still want copper, there's a hot water 
tank at five, which just went out this morning, she won't mind at all if you ask her, she's really nice.' Those sorts of connections... (Orkney, Craft Practitioner 7).

The importance of physical social relationships and networks was a recurring theme across the island communities.

And I miss that feedback you get from working with somebody else because I'm not in Stromness or Kirkwall, you know in Stromness you tend to be seeing people in the street or meeting people at openings and things, I tend not to be able to do that (Orkney, Craft Practitioner 9).

It's about drawing people in and then carrying on. So our sustainable project on Shapinsay started with a workshop but now it's a self-sustaining community of artists on Shapinsay that we just go back and work with sometimes and we're taking that onto Sanday at some point in the summer, using the same kind of model but do something exciting to draw people in - see who comes along - and what they'd like (Orkney, Craft Practitioner 7).

Island appreciation and the indigenous market for authentic craft and vernacular materials was referred to in participant narratives.

Shetlanders have been really good. I thought I might do stuff and tourists will buy it but it's amazing how many Shetlanders buy it. I think the arts and crafts, certainly the big craft fair they hae at Clickimin, the Christmas one, we're really lucky that Shetlanders support that so well. I think speaking to other glass artists down south, it's not always the case that craft fairs are so well supported and I think that people - I'm not saying that all prices are high - some say the prices could be higher, but I think people are willing to pay money for quality goods and they don't want to haggle. You hear some horror stories from other craft fairs when 
they are haggling, so I think they are really supportive (Shetland Creative

Practitioner 6).

The rich and heterogeneous networks and relationships within local communities were characterised by deep ties enabling valuable exchanges. These insights underpin the examination and understanding of the complex characteristics of craft and cultural production within island contexts. The time spent in developing networks and engaging with the craft community was also drawn upon by participants as a key strength, with one explaining:

They don't see you as competition, they just see you as being somebody that's helping push the whole standard up and the prices up and you are adding to the craft community. Just getting together with them is a really good thing (Shetland, Creative Practitioner 6).

These rich networks and deep ties are distinct in small communities through the repetition of complex patterns, which underpin reciprocal relationships between craft practitioners. Local craft production can be conceptualised as having a concern with the complexities, conflicts and challenges of contemporary society and culture. This more expansive view of craft situates the relationship craft makers have to their local context and how they relate to the material world. Craft objects as cultural assets are important sources of cultural appreciation, personal meaning and contextually located knowledge and resources. Relationships to place-based craft production is interesting because of the way practitioners express and mediate social and cultural relationships. From this, it can be asserted that in addition to seeing craft as a list of attributes, these relations rooted in local cultural heritage are the essence of the lived experience of craft practice in everyday lives. 


\section{Policy dissonance}

Arising from our work in the Northern Isles, we identified a dissonance between national and international creative and cultural industries policies and the political economy of the lived experience of craft work in non-urban settings. In complex geographies like the Northern Isles the local production of craft is predicated on collaborative networks and collectives that operate in ways that are distinct from those conceived of in UK creative and cultural industries policy (often the global creative clusters of London and the South East or the physical creative hubs of post-industrial Northern UK cities). Complex embedded reciprocal relationships, best supported at the local level, underpin the argument for greater devolution of funding and local "grassroots" support that is contextually relevant. It is worthy of note that of the 121 Creative Scotland (2018) Regularly Funded network, four are craft organisations with one based outwith the central belt of Scotland and none in island communities. This foregrounds questions around the dominant model of economic growth as a vehicle to support the production of craft in distributed communities. We advocate for what we term, fractal growth, which is growth and development that considers multiple dimensions, as an emerging concept to support the local production of craft. Craft practitioners and businesses are often small and are either not keen to scale up or are limited by their location and capacity, which oftentimes creates the intrinsic value of such craft objects.

I need more time to develop more ranges and new...so when you are running a business it's very difficult to find that time to keep coming up with new designs. I suppose ideally I could do with somebody helping me with design development so I don't have that luxury at the moment, we just manage as we are... (Orkney, Craft Practitioner 5). 
My capacity to produce is pretty limited. So that would affect the amount of touchpoints that I would have because I'm no able to exhibit in too many different places (Shetland, Craft Practitioner 5).

And that's very difficult, being a one-man band you haven't got a secretary who says 'here's your final statement and then you get a solicitor's letter', I know I can't chase people up who don't pay and that's happened very recently (Orkney, Craft Practitioner 9).

I've kept the business quite small and working around the family and my community commitments, now our youngest is twelve - going on thirteen, so it's kinda... it's a fine time to try and tak it to the next level (Shetland, Craft Practitioner 6).

We posit that the economic production of craft and its deep connection to locality has been undervalued in policy. We maintain that the economic production of craft as cultural assets can contribute to cultural heritage, community engagement, protection of hand skills, and sustainability and wellbeing that is socially, culturally and environmentally beneficial to the creative and cultural economy in island communities.

\section{Conclusions, Limitations and Future Research}

This article has outlined the rationale for crafting the local and developing a deeper understanding of the lived experience of craft work in the Northern Isles of Scotland. Various politics of place-based initiatives have centred on the lack of innovation and infrastructure in non-metropolitan regions. Drawing on accounts from island-based craft and creative practitioners active in the craft and creative sector we contend that a more 
nuanced approach that considers the nexus of socio-cultural relations located in placebased perspectives; temporal and spatial perspectives; and collaborative and collective perspectives may contribute to more equitable and inclusive models of support and funding for craft work. This idea is the basis of emerging theory on the political economy of craft and a recasting of discourses around growth.

We further argue for future investigation into, what we term, fractal growth growth and development that considers multiple dimensions - as being a valid and valuable outcome of innovation, based on the repetition of complex patterns of creative production and knowledge weaving, which cannot be scaled and internationalised easily. Drawing on Carayannis et al's (2012) concept of innovation that includes: natural environments [of society]; civil society; governments; economy; and higher education we support their contention that knowledge and innovation can create synergies between economy, society and democracy in the pursuit of the advancement of quality of life. This notion of multi-level, multi-modal, multi-nodal configurations of dynamic tangible and intangible cultural assets underpins the framing of fractal growth, which emphasises value beyond solely an economic imperative. These can loosely be described as forms of rhizome-like growth embodied within culturally located placebased perspectives; temporal and spatial perspectives; and collaborative and collective perspectives related to the local and lived experience of creative practitioners.

The contention being that the emphasis within policy has been the support of growth and scalability as a defining construct in contemporary culture and in cultural policy. Future research will aim to develop the concept of fractal growth and further insights around knowledge weaving as a fulcrum between the local and lived experience of craft work towards supporting collective cultural capital and the systemic 
development of the creative economy within a regional ecology of local cultural and economic activities, which cannot be easily scaled.

\section{Acknowledgements}

Funded by the AHRC: Grant number AH/P013325/1 and with thanks to the stakeholders and participants in DING across the H\&I region.

\section{References}

Abrams, L. (2006). Knitting, Autonomy and Identity: The role of hand-knitting in the construction of women's sense of self in an island community, Shetland, c. 1850-2000. Textile History, 37(2), 149-165.

AHRC. (2017). Creative Exchanges: The AHRC Knowledge Exchange Hubs for the Creative Economy Report, Swindon: AHRC.

AHRC. (2017). Creative Industries Clusters Programme - Creative Research and Development (R\&D) Partnerships, Call Specification Stage 1, Available at https://ahrc.ukri.org/documents/calls/creative-industries-clusters-programme-call-spec/ Bakhshi H. and Cunningham, S. (2016). Cultural Policy in the Time of the Creative Industries, London: NESTA.

Banks, M. (2018). Creative economies of tomorrow? Limits to growth and the uncertain future, Cultural Trends, 27(5), 367-380.

BEIS (2017) Industrial Strategy: Building a Britain fit for the Future, Available at https://assets.publishing.service.gov.uk/government/uploads/system/uploads/attachment _data/file/664563/industrial-strategy-white-paper-web-ready-version.pdf BEIS and DCMS (2018) Industrial Strategy Creative Industries Sector Deal, Available at

https://assets.publishing.service.gov.uk/government/uploads/system/uploads/attachment _data/file/695097/creative-industries-sector-deal-print.pdf 
Bell D. and Jayne, M. (2010) The creative countryside: Policy and practice in the UK rural cultural economy Journal of Rural Studies 26, 209-218

BOP Consulting. (2012). Craft in an Age of Change, Commissioned by Crafts Council, Bunn, S. (2016) Who Designs Scottish Vernacular Baskets? Journal of Design History, $29(1), 24-42$

Carayannis, E.G, Barth, T.D. and Campbell D., (2012) The Quintuple Helix innovation model Journal of Innovation and Entrepreneurship, Available at https://innovationentrepreneurship.springeropen.com/articles/10.1186/2192-5372-1-2

Creative Scotland, Arts Council of Wales, and Craft Northern Ireland, London: BOP Consulting.

Creative Scotland (2018) Craft - Regular Funding 2018-21, Available at https://www.creativescotland.com/funding/latest-information/fundedorganisations/regular-funding-2018-21/overviews/craft

Crossick, G. \& Kaszynska, P. (2016). Understanding the value of arts \& culture: The AHRC Cultural Value Project, London: AHRC.

DCMS. (1998). Creative industries mapping document: crafts, available at https://assets.publishing.service.gov.uk/government/uploads/system/uploads/attachment _data/file/193575/Creative_Industries_Mapping_Document_Crafts.pdf:

DCMS. (2016). Creative Industries Economic Estimates, Available at https://assets.publishing.service.gov.uk/government/uploads/system/uploads/attachment _data/file/523024/Creative_Industries_Economic_Estimates_January_2016_Updated_2 01605.pdf

DCMS. (2018). DCMS Sectors Economic Estimates 2017, Available at https://assets.publishing.service.gov.uk/government/uploads/system/uploads/attachment 
_data/file/759707/DCMS_Sectors_Economic_Estimates_2017_provisional_GVA.pdf DCMS.

Garnham, N. (2005). From Cultural to Creative Industries. International Journal of Cultural Policy 11 (1): 15-29.

Gibson, C. (2012) Introduction - Creative Geographies: tales from the 'margins' in Gibson, C. (Ed) Creativity in Peripheral Places, Abingdon: Routledge.

Glasgow Centre for Population Health \& Scottish Community Development Centre (2015). Positive conversations, meaningful change: learning from animating assets. Glasgow Centre for Population Health. Available at:

http://www.gcph.co.uk/publications/598_positive_conversations_meaningful_change_le arning_from_animating_assets

Highlands and Islands Enterprise (2013) Creative Industries Strategy, 2014 - 2019, Highlands and Islands Enterprise, Inverness.

Ingold, T. (2013). Making. London: Routledge.

Jakob, D., \& Thomas, N.J. (2015). Firing up craft capital: the renaissance of craft and craft policy in the United Kingdom. International Journal of Cultural Policy, 23(4), 495-511.

Luckman, S., Gibson, C., and Lea, T. (2009). Mosquitoes in the mix: How transferable is creative city thinking? Singapore Journal of Tropical Geography 30, 70-85.

Luckman, S. (2012). Locating cultural work: the politics and poetics of rural, regional and remote creativity. London: Palgrave Macmillan.

Luckman, S. (2013). The aura of the analogue in a digital age; women's crafts, creative markets and home-based labour after etsy. Cultural Studies Review, 19(1), 249-70. Luckman, S. (2015). Craft and the creative economy. New York: Palgrave Macmillan. Luckman, S. and Thomas, N. (Eds.). (2018). Craft Economies, London: Bloomsbury. 
Luckman, S., Andrew, J. and Crisp, T. (2018). Crafting Self: Promoting the making self in the creative micro-economy, Adelaide: School of Creative Industries, University of South Australia.

Manzini, E. (2015). Design, when everybody designs: An introduction to design for social innovation. Cambridge: MIT Press.

Markusen, A. (2007). An arts-based state rural development policy, special issue on state rural development policy. The Journal of Regional Analysis and Policy, 37(1), 710.

McHattie, L.S., MacLean, D., \& Dixon, B. (2013). Design innovation: experimental creative research approaches. Paper presented to the IASDR 2013 Conference. Tokyo, Japan, August.

McHattie, L., Champion, K. and Broadley, C., (2018). Craft, Textiles and Cultural Assets: Design innovation in the Northern Isles of Scotland, Island Studies Journal Special Issue Textiles and Clothing, 13(2): 39-54.

Nesta. (2007). Rural Innovation. London: NESTA.

Oakley, K. and O’Connor, J. (2015). Introduction. In: Oakley K and O’Connor J (Eds.). The Routledge Companion to the Cultural Industries. London: Routledge: 1-32. O’Connor, J. (2016). After the Creative Industries: Cultural Policy in Crisis. Law, Social Justice \& Global Development (1): 1-18.

Pratt, A. (2009). Policy Transfer and the Field of the Cultural and Creative Industries: What Can Be Learned from Europe? In Kong, L. and O’Connor, J. (Eds.). Creative Economies, Creative Cities Asian-European Perspectives, Dordrecht: Springer. Roberts, E., \& Townsend, L. (2016). The contribution of the creative economy to the resilience of rural communities: Exploring cultural and digital capital. Sociologic Ruralis, 56(2), 197- 219. 
Scottish Government (2018). A culture strategy for Scotland, Available at https://www.gov.scot/publications/culture-strategy-scotland-draft-consultation/ Senior, T., Cooper, R., Dovey, J., Follett, G., Shiach, M. (2016). Connecting to Innovate: A Preliminary Report on the Achievements of the AHRC Knowledge Exchange Hubs for the Creative Economy. Swindon: AHRC.

Sennett, R. (2009). The Craftsman. London: Penguin.

TBR. (2014). Measuring the craft economy: defining and measuring craft: report 3. London: The Crafts Council.

Turney, J. (2009). The culture of knitting. London: Berg.

Yair, K. (2011). Craft and rural development. London: Crafts Council. 